\title{
Axon Sorting within the Spinal Cord Marginal Zone via Robo-Mediated Inhibition of N-Cadherin Controls Spinocerebellar Tract Formation
}

\author{
Nozomi Sakai, ${ }^{1}$ Ryan Insolera, ${ }^{3,4}$ Roy V. Sillitoe, ${ }^{1}$ Song-Hai Shi, ${ }^{3,4}$ and Zaven Kaprielian ${ }^{1,2}$ \\ ${ }^{1}$ Dominick P. Purpura Department of Neuroscience and 2Department of Pathology, Albert Einstein College of Medicine, Bronx, New York, 10461; \\ ${ }^{3}$ Developmental Biology Program, Memorial Sloan-Kettering Cancer Center, New York, New York 10065; and ${ }^{4}$ Neuroscience Graduate Program, Weill \\ Cornell Medical College, New York, New York 10065
}

The axons of spinal projection neurons transmit sensory information to the brain by ascending within highly organized longitudinal tracts. However, the molecular mechanisms that control the sorting of these axons within the spinal cord and their directed growth to poorly defined targets are not understood. Here, we show that an interplay between Robo and the cell adhesion molecule, N-cadherin, sorts spinal commissural axons into appropriate longitudinal tracts within the spinal cord, and thereby facilitates their brain targeting. Specifically, we show that $\mathrm{d} 1$ and $\mathrm{d} 2$ spinal commissural axons join the lateral funiculus within the spinal cord and target the cerebellum in chick embryos, and that these axons contribute to the spinocerebellar projection in transgenic reporter mice. Disabling Robo signaling or overexpressing $\mathrm{N}$-cadherin on these axons prevents the formation of the lateral funiculus and the spinocerebellar tract, and simultaneously perturbing Robo and N-cadherin function rescues both phenotypes in chick embryos. Consistent with these observations, disabling Robo function in conditional N-cadherin knock-out mice results in a wild-type-like lateral funiculus. Together, these findings suggest that spinal projection axons must be sorted into distinct longitudinal tracts within the spinal cord proper to project to their brain targets.

\section{Introduction}

The stereotypical growth of axons to their synaptic targets is a crucial phase of neural circuit formation. In the vertebrate spinal cord, ascending projection neurons extend axons into the marginal zone where they are arranged within distinct longitudinal tracts, based on the locations of their brain targets (Brodal, 1998; Willis, 2007). Topographically organized axonal projections establish stereotyped patterns of connectivity throughout the nervous system and can define the routes that axons follow to reach their synaptic targets (Garel and Rubenstein, 2004; Luo and

\section{Received May 9, 2012; revised Aug. 23, 2012; accepted Sept. 3, 2012}

Author contributions: N.S. and Z.K. designed research; N.S., R.I., and R.V.S. performed research; N.S. and S.-H.S. contributed unpublished reagents/analytic tools; N.S. analyzed data; N.S. and Z.K. wrote the paper.

This work was supported by grants from the National Institutes of Health, National Institute of Neurological Disorders and Stroke (R01NS038505), and the New Jersey Commission on Spinal Cord Research (CSCR11IRG011) (Z.K.). We thank the following investigators for constructs: Janice Imai, Tohru Yamamoto, Roger Bradley, Deanna Benson, and Allan Bradley. We also thank Stacey Reeber for her assistance with mouse work. We are grateful to Carol Mason, Jane Dodd, Jane Johnson, Yimin Zou, Hannes Bülow, Jean Hébert, Scott Emmons, Marie Fernandes, Cristina Aguirre-Chen, and Angela Jevince for providing critical and insightful comments on the manuscript. Anti-mouse Ncad (6B3) was obtained from the Developmental Studies Hybridoma Bank, developed under the auspices of the National Institute of Child Health and Human Development and maintained by the University of lowa, Department of Biological Sciences (lowa City, IA).

R.V. Sillitoe's present address: Department of Pathology and Immunology, Baylor College of Medicine, Jan and Dan Duncan Neurological Research Institute of Texas Children's Hospital, Houston, TX 77030.

The authors declare no competing financial interests.

Correspondence should be addressed to Zaven Kaprielian, Dominick P. Purpura Department of Neuroscience and Department of Pathology, Albert Einstein College of Medicine, Kennedy Center Room 624, 1410 Pelham Parkway South, Bronx, NY 10461. E-mail: zaven.kaprielian@einstein.yu.edu.

DOI:10.1523/JNEUROSCI.2225-12.2012

Copyright $\odot 2012$ the authors $\quad 0270-6474 / 12 / 3215377-11 \$ 15.00 / 0$
Flanagan, 2007; Sakano, 2010). Accordingly, the spatial arrangement of ascending axons within distinct longitudinal funiculi in the spinal cord proper may dictate their long-range projections to appropriate brain targets.

Dorsal spinal commissural neurons are a major class of projection neurons whose axons cross the midline en route to the brain (Brodal, 1998). Although some evidence suggests that Atoh1-derived d1 axons project to the cerebellum (Bermingham et al., 2001), the brain targets of genetically distinct classes of dorsal spinal neurons have not been explicitly identified. After crossing the midline, most spinal commissural axons execute a rostral turn and project along a medial longitudinal commissural (MLc) trajectory adjacent to the floor plate and form the ventral funiculus (VF) (Bovolenta and Dodd, 1990; Imondi and Kaprielian, 2001; Kadison and Kaprielian, 2004). A subset of these axons, termed intermediate longitudinal commissural (ILc) axons, ultimately leave the VF and project in an arcuate manner into the lateral funiculus (LF).

The relative positioning of longitudinal axon tracts in the vertebrate spinal cord is in part controlled by the Robo-Slit guidance system. In the chick spinal cord, postcrossing spinal commissural axons lacking Robo signaling fail to elaborate ILc projections and, instead, extend in hyperfasciculated MLc tracts within the VF (Reeber et al., 2008). A similar phenotype is observed in the spinal cord of mouse embryos lacking Robo1 and Robo2 or all three Slits (Long et al., 2004; Jaworski et al., 2010). Nevertheless, the molecular mechanisms that confine postcrossing commissural axons to the contralateral VF in the absence of Robo function are not 
known. The cell adhesion molecule, N-cadherin (Ncad) is required for the proper positioning of longitudinal axon tracts in Drosophila (Iwai et al., 1997), and Robos are capable of attenuating Ncad function in a variety of systems (Rhee et al., 2002, 2007; Wong et al., 2012). Thus, it is conceivable that Robo-mediated inhibition of Ncad-dependent fasciculation regulates funiculi formation in the developing CNS.

Here, we use genetic labeling strategies to show that dorsal spinal $\mathrm{d} 1$ and $\mathrm{d} 2$ axons project to multiple brain regions including the cerebellum. Moreover, we show that disabling Robo signaling or overexpressing Ncad on spinal commissural axons prevents these axons from joining the LF, and subsequently disrupts spinocerebellar tract formation. Importantly, the simultaneous perturbation of Robo and Ncad function rescues these axon positioning and targeting phenotypes. Together, our findings suggest that Robo-mediated inhibition of Ncad is required for sorting spinal projection neuron axons into distinct longitudinal tracts and that this facilitates their projection to the cerebellum.

\section{Materials and Methods}

Animals. Fertilized White Leghorn eggs were obtained from Charles River and incubated at $39^{\circ} \mathrm{C}$. Ncad ${ }^{\text {flox }}$ (Kostetskii et al., 2005), Atoh1CreER ${ }^{T 2}$ (Machold and Fishell, 2005), Neurog1CreER ${ }^{T 2}$ (Koundakjian et al., 2007), and Rosa26-lac $Z^{\text {flox }}$ (Soriano, 1999) mice were obtained from the The Jackson Laboratory.

In ovo and in utero electroporation. For in ovo electroporation, plasmid construct(s) either alone or together with morpholinos (see below) were injected into the central canal of E2.5-E3.5 chick neural tubes. Unilateral transfection of the spinal cord was performed by applying five $20-21 \mathrm{~V}$ pulses for $50 \mathrm{~ms}$ at $100 \mathrm{~ms}$ intervals (Krull, 2004). In utero electroporation was performed as previously described (Bultje et al., 2009) except that plasmids were injected into the central canal of E11-E11.5 mouse embryos, and five $40 \mathrm{~V} 50 \mathrm{~ms}$ pulses at $950 \mathrm{~ms}$ intervals were applied to the spinal cord. Chick and mouse embryos of either sex were used for electroporation.

Plasmid constructs and morpholinos. The $c \beta$ actin-NcadFL construct (a gift from R. Bradley), which contains a chick $\beta$-actin promoter, was used to overexpress the full-length form of chick Ncad. The following plasmids containing a CAG promoter (Niwa et al., 1991) were used for manipulating gene function via electroporation: CAG-humanRobol $\Delta C$ GFP (Hammond et al., 2005; Reeber et al., 2008) and CAG-xenopusNcad $\Delta E$ myc (Bozdagi et al., 2004). We used CAG-nlsCre-IRES-GFP for eliminating Ncad expression in Ncad flox mice and CAG-IRES-GFP as the corresponding control, and delivered these plasmids into mouse embryos via in utero electroporation. CAG-Robo1 $\Delta C$-taumCherry was constructed by replacing the GFP sequence in CAG-Robol $\triangle C$-GFP plasmid (Hammond et al., 2005) with taumCherry, which was obtained by PCR from a NeurogltaumCherry construct (Reeber et al., 2008). We used AtohltauGFP or AtohltaumCherry, and Neurog1tauGFP or Neurog1taumCherry plasmids as reporter constructs to visualize the cell bodies and axons of $\mathrm{d} 1$ and $\mathrm{d} 2$ neurons, respectively (Lumpkin et al., 2003; Nakada et al., 2004; Reeber et al., 2008). The Neurog1-reporter construct contains a previously described $0.8 \mathrm{~kb}$ dorsal-specific enhancer element, TgN1-13 (Nakada et al., 2004; Reeber et al., 2008). We used CAG-tauGFP and CAGtaumCherry, in which tauGFP and taumCherry sequences from Neurog1tauGFP and Neurog1taumCherry, respectively, were subcloned into the $P P B-C A G$ vector (Yusa et al., 2009), as well as $C A G-$ GPI-AP, which expresses GPI-anchored human placental alkaline phosphatase (AP; Arakawa et al., 2008), as pan neuronal/axonal markers. Ncad and standard control morpholino oligomers (MO) with 3 '-fluorescein or lissamine tags were obtained from Gene Tools. The antisense oligo sequence for the Ncad MO is $5^{\prime}$ GCGGCGTTCCCGCTATCCGGCACAT-3', which targets the translational start region of chick Ncad (Shiau and Bronner-Fraser, 2009).
Histochemistry. All fluorescence immunostaining was performed on 20-50 $\mu \mathrm{m}$ cryosections as previously described (Jevince et al., 2006). Primary antibodies used for immunohistochemistry were anti-mouse Ncad (6B3, 1:5; Developmental Studies Hybridoma Bank) and antirabbit $\beta$-galactosidase ( $\beta$-gal, 1:500; AbD Serotec). Appropriate Alexa Fluor 488, 568, (1:1000; Invitrogen) or Cy3 (1:200; Jackson ImmunoResearch) conjugates were used as secondary antibodies. For 3,3'-diaminobenzidine (DAB) photoconversion of fluorescence signals, we stained, as whole mounts, CNS tissues transfected with the d1 or d2 reporter, with anti-rabbit green fluorescent protein (GFP, 1:1000; Invitrogen), and subsequently with biotin-conjugated antirabbit secondary antibody (1:50; Vector Laboratories). The tissue was further incubated with avidin-biotin-peroxide complex and processed for $\mathrm{DAB}$ reaction (Vector Laboratories) as previously described (Jevince et al., 2006). AP reaction in whole mounts of CNS transfected with $C A G-G P I-A P$ was performed as previously described (Imondi et al., 2000; Arakawa et al., 2008). For $\beta$-gal staining, $20 \mu \mathrm{m}$ cryosections from P6 lacZ-reporter mice were fixed in cold $4 \%$ paraformaldehyde for $5 \mathrm{~min}$, washed in 5-bromo-4-chloro-3-indolyl- $\beta$ D-galactopyranoside (X-gal) washing buffer, which contains $2 \mathrm{~mm}$ $\mathrm{MgCl}_{2}, 0.05 \%$ sodium deoxycholate, and $0.1 \%$ Igepal Ca-630 (SigmaAldrich) in PBS, two times for $10 \mathrm{~min}$ at $25^{\circ} \mathrm{C}$, and incubated in $\mathrm{X}$-gal reaction solution $\left(1 \mathrm{mg} / \mathrm{ml} \mathrm{X}\right.$-gal, $5 \mathrm{~mm} \mathrm{~K}_{3} \mathrm{Fe}(\mathrm{CN})_{6}$ and $5 \mathrm{~mm}$ $\mathrm{K}_{4} \mathrm{Fe}(\mathrm{CN})_{6} \cdot{ }^{3} \mathrm{H}_{2} \mathrm{O}$ in X-gal washing buffer) at $37^{\circ} \mathrm{C}$ for $12-18 \mathrm{~h}$.

Lineage mapping and retrograde tracing. To carry out fate mapping, we crossed Rosa26-lac $Z^{\text {flox }}$ Cre reporter mice with Atoh1CreER ${ }^{T 2}$ or Neurog1CreER ${ }^{T 2}$ mice. Tamoxifen (Sigma-Aldrich) in corn oil was administered by oral gavage at $2-4 \mathrm{mg}$ per $40 \mathrm{~g}$ of $10.5 \mathrm{~d}$ pregnant mice. At $\mathrm{P} 4$, pups were genotyped for CreER alleles by PCR with following primers: forward 5'-GCCTGGTCTGGACACAGTGCC-3' and reverse 5' -CT GTCTGCCAGGTTGGTCAGTAAGC-3'. Genotyping of Rosa26-lac Zflox was performed as described previously (Soriano, 1999). $\beta$-Gal staining of Atoh1CreER;Rosa26-lac flox mice spinal cord was performed at P6 as described above. For retrograde tracing of spinocerebellar axons/tracts originating from Atoh 1 progenitor-derived d 1 and Neurog1-lineage neurons, we injected $2 \%$ Alexa Fluor 555-conjugated wheat germ agglutinin (WGA) tracer (Invitrogen) in PBS into lobules V-VIII of the cerebellum of P5 Atoh1CreER;Rosa26-lac Zflox and Neurog1CreER;Rosa26-lac Z $Z^{\text {flox }}$ pups. The surgery was conducted as previously described (Reeber et al., 2011). For colabeling, $1 \mathrm{~d}$ later, at P6, we dissected out the spinal cord and performed anti- $\beta$-gal immunostaining of cryosections as described above.

Photodocumentation. Epifluorescence images were captured using a Nikon Eclipse TE300 microscope. The confocal images were obtained using a Fluoview 500 microscope (Olympus) and processed with ImageJ64 (National Institutes of Health). The images of DAB- or APstained CNS whole mounts were acquired on a Zeiss Stemi-2000C stereo dissecting microscope (Carl Zeiss). Brightness and contrast of images were adjusted using Adobe Photoshop CS.

Quantification and data analysis. For quantification of d2 ILc axons, we selected a $0.5 \mathrm{~mm}^{2}$ region in the center of the electroporated area of a given open-book preparation. All labeled decussated axons that did not project parallel to, and in the vicinity of, the floor plate were regarded as ILc axons. We first normalized $\mathrm{d} 2$ commissural axon counts, defined as the number of labeled $\mathrm{d} 2$ axons within the floor plate, to the respective counts of transfected cell bodies, and verified that the resulting ratios were comparable across preparations. The numbers of $\mathrm{d} 2$ ILc axons were normalized to the total number of labeled $\mathrm{d} 2$ commissural axons. For quantification of spinal cord-derived axons in the brain, the numbers of ipsilaterally and contralaterally projecting $\mathrm{d} 1$ and $\mathrm{d} 2$ axons were counted in the hindbrain, cerebellum, and around the isthmus at the hindbrain-midbrain border. In the hindbrain, only rostrally projecting axons were counted. Rostrally projecting axons anterior to the cerebellar peduncles of the spinocerebellar tract were counted as axons projecting to the isthmus. In each case, axon counts were normalized to the corresponding numbers of all transfected cell bodies in a given spinal cord. All data analyses were performed using the unpaired Student's $t$ test and GraphPad Prism (Version 5.0d), and $p<0.05$ was considered statistically significant. 


\section{Results}

$\mathrm{d} 1$ and $\mathrm{d} 2$ axons project to the chick hindbrain, cerebellum, and isthmus along MLc and ILc trajectories

After crossing the midline, ascending $\mathrm{d} 1$ and $\mathrm{d} 2$ dorsal spinal commissural axons contribute to both the VF and LF by projecting along MLc and ILc trajectories, respectively, within the spinal cord marginal zone (Reeber et al., 2008; Avraham et al., 2009) (Fig. 1J). However, the brain targets of these neurons have not been explicitly identified, and whether the positioning of the corresponding axons within particular funiculi in the spinal cord proper influences their projection to these targets has not been addressed. Toward investigating these issues we first performed unilateral in ovo electroporation with specific reporter constructs (Lumpkin et al., 2003; Nakada et al., 2004; Reeber et al., 2008) to identify the brain targets of d1 and $\mathrm{d} 2$ neurons/axons in chick embryos. Specifically, we analyzed the long-range projections of $\mathrm{d} 1$ and $\mathrm{d} 2$ axons in whole-mount preparations derived from the electroporated embryos by photoconverting the GFP labeling of $\mathrm{d} 1$ and $\mathrm{d} 2$ axons to more robust colorimetric signals (Fig. $1 A-H, J$ ). The perdurance of reporter expression made it possible to trace $\mathrm{d} 1$ and $\mathrm{d} 2$ axons in embryos electroporated at E2.5-E3 and harvested as late as E10-E14. The majority of $\mathrm{d} 1$ and $\mathrm{d} 2$ axons projected anteriorly, and these axons were readily visible as far rostrally as the isthmus or hindbrain-midbrain border located between the cerebellum and tectum, on both the contralateral and ipsilateral (electroporated) sides of the spinal cord (Fig. $1 \mathrm{~A}-\mathrm{H}, \mathrm{J}$ ). Importantly, most $\mathrm{d} 1$ and $\mathrm{d} 2$ axons within the LF projected to the cerebellum, forming the inferior portion of the cerebellar peduncles (Fig. $1 A-D, G, J$ ), whereas the majority of these axons within the VF projected further rostrally to the isthmus (Fig. $1 A-H, J$ ).

To further characterize the projections of $\mathrm{d} 1$ and $\mathrm{d} 2$ axons as they extend to their brain targets, we quantified the number of longitudinally projecting axons that reached the hindbrain (Fig. $1 C, F, I$ ), cerebellum (Fig. $1 D, G, I$ ), and the isthmus (Fig. $1 E, H, I)$, on both the contralateral and ipsilateral sides of the electroporated embryos. In all cases, the numbers of labeled axons were normalized to the numbers of transfected neurons (Fig. $1 I)$. Of the axons that reached the hindbrain, the small number (and/or collaterals emanating from these axons), which executed a ventral turn within the hindbrain proper, were excluded from the quantification (Fig. 1C,F). Together, our findings show that $\mathrm{d} 1$ and $\mathrm{d} 2$ spinal axons project to at least three distinct brain regions through the VF and LF (Fig. $1 K$ ) and that similar numbers of these axons project to a given region.

\section{Retrograde labeling of spinocerebellar tract: Atoh1 and Neurog1 progenitor-derived neurons project to the cerebellum in mice}

To further confirm that $\mathrm{d} 1$ and $\mathrm{d} 2$ axons target the cerebellum, we performed retrograde tracing of spinocerebellar axons in postnatal Atoh1 (Atoh1CreER;Rosa26-Lac $Z^{\text {flox }}$ ) (Soriano, 1999; Machold and Fishell, 2005) and Neurog1 (Neurog1CreER;Rosa26lac $Z^{\text {flox }}$ ) (Koundakjian et al., 2007) reporter mice following tamoxifen administration at E10.5. Specifically, we injected Alexa Fluor 555-conjugated WGA into the cerebellum of P5 Atoh1CreER;Rosa26-LacZ flox $^{\text {and Neurog1CreER;Rosa26-lacZ flox }}$ mice. Subsequently, X-gal staining and/or $\beta$-gal expression in spinal cord sections obtained from these animals at P6 was used to visualize fate-mapped Atoh 1 progenitor-derived d 1 and Neurog1 progenitor-derived neurons (Fig. $2 A, B, D, E, G$ ). These analyses revealed that a subset of $\beta$-gal-expressing Atoh1- and Neurog1-derived cell bodies was colabeled with the retrogradely transported WGA tracer in the spinal cord (Fig. $2 B-G$ ). Among 9 $\beta$-gal-positive $\mathrm{d} 1$ neurons contained within one side of a given spinal cord section, $\sim 4$ cell bodies colabeled with retrogradely transferred WGA, whereas $\sim 6$ cells of 45 labeled Neurong1 progenitor-derived neurons were also labeled with WGA. Given that the colabeled cell bodies were located in lamina VI and VII of Atoh1CreER;Rosa26-LacZ $Z^{\text {flox }}$ (Fig. 2B-D) and Neurog1CreER; Rosa26-Lac $Z^{\text {flox }}$ (Fig. 2E-G) mice, respectively, and both laminae contain spinocerebellar neurons in mammals (Brodal, 1998; Xu and Grant, 2005), these findings indicate that, just as in chick embryos, $\mathrm{d} 1$ and $\mathrm{d} 2$ axons contribute to the spinocerebellar tract in mice.

\section{Overexpression of Ncad results in a reduction of ILc axons within the LF, phenocopying the effects of disabling Robo-Slit signaling}

Toward determining how the axons of spinal projection neurons project to their brain targets, we next investigated the molecular mechanisms that sort these axons into distinct longitudinal tracts within the spinal cord proper. As a consequence of disabling RoboSlit signaling in the chick spinal cord, decussated commissural axons fail to grow away from the ventral midline along ILc trajectories and, instead, exclusively extend adjacent to the floor plate as MLc projections in the VF (Reeber et al., 2008) (Fig. 3A,E,H). To explore the possibility that Robo-mediated inhibition of Ncad (see Introduction) might account for this phenotype, we first investigated the distribution of Ncad in the chick spinal cord. Ncad is expressed on spinal commissural axons, including those extended by genetically distinct $\mathrm{d} 1$ and $\mathrm{d} 2$ neurons (data not shown; Fig. $3 \mathrm{~B}, \mathrm{C}$ ). These observations raised the possibility that postcrossing spinal commissural axons hyperfasciculate within the VF in an Ncad-dependent manner following the disruption of Robo-Slit signaling (Fig. 3A). A straightforward prediction of this hypothesis is that overexpression of full-length Ncad (NcadFL) on commissural axons would abrogate Robo-mediated inhibition of Ncad, leading to an increase in MLc axons and a corresponding decrease in ILc axons, effectively recapitulating the pathfinding phenotype that results from disrupting Robo-Slit signaling.

As a first step toward testing this prediction, we asked whether it would be possible to overexpress Ncad on spinal commissural axons in vivo via unilateral electroporation of E3-E3.5 chick embryos with a chick NcadFL expression construct and a $C A G$ tauGFP pan-axonal reporter plasmid. At E4.5, immunostaining with anti-chick Ncad confirmed an increased level of Ncad expression on tauGFP-labeled commissural axons on the transfected side of the spinal cord (Fig. $3 C$ ). We then coexpressed NcadFL and a pan-axonal marker, CAG-taumCherry, or the $\mathrm{d} 2$ reporter (Neurog1taumCherry) to assess the consequences of overexpressing Ncad on the axons of all transfected neurons or only the $\mathrm{d} 2$ subset. It is important to note that electroporation of either the pan-neuronal/axonal or the $\mathrm{d} 2$ reporter labels both ILc and MLc projections (Reeber et al., 2008) (Fig. 3 D, G). Also, here and throughout this study we quantified the various misexpression phenotypes by selectively counting the numbers of $\mathrm{d} 2$ axons. Three days after coelectroporating E3 chick embryos with NcadFL and pan-axonal or $\mathrm{d} 2$ reporter constructs we observed a significant reduction in the numbers of ILc axons and an abnormally thick MLc axon bundle in open-book preparations derived from these embryos (Fig. $3 F, I$ ). Consistent with a potential role for Robo inhibition of Ncad adhesion in directing a subset of postcrossing commissural axons along ILc trajectories and into the LF, these defects resemble those observed in embryos electroporated with a cytoplasmic truncation (dominant-negative form) of Robo, CAG-Robo1 $\triangle C$-GFP (Fig. $3 E, H$ ). 
A

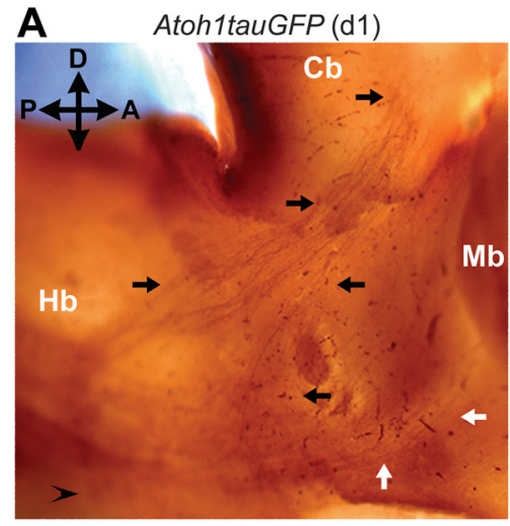

B
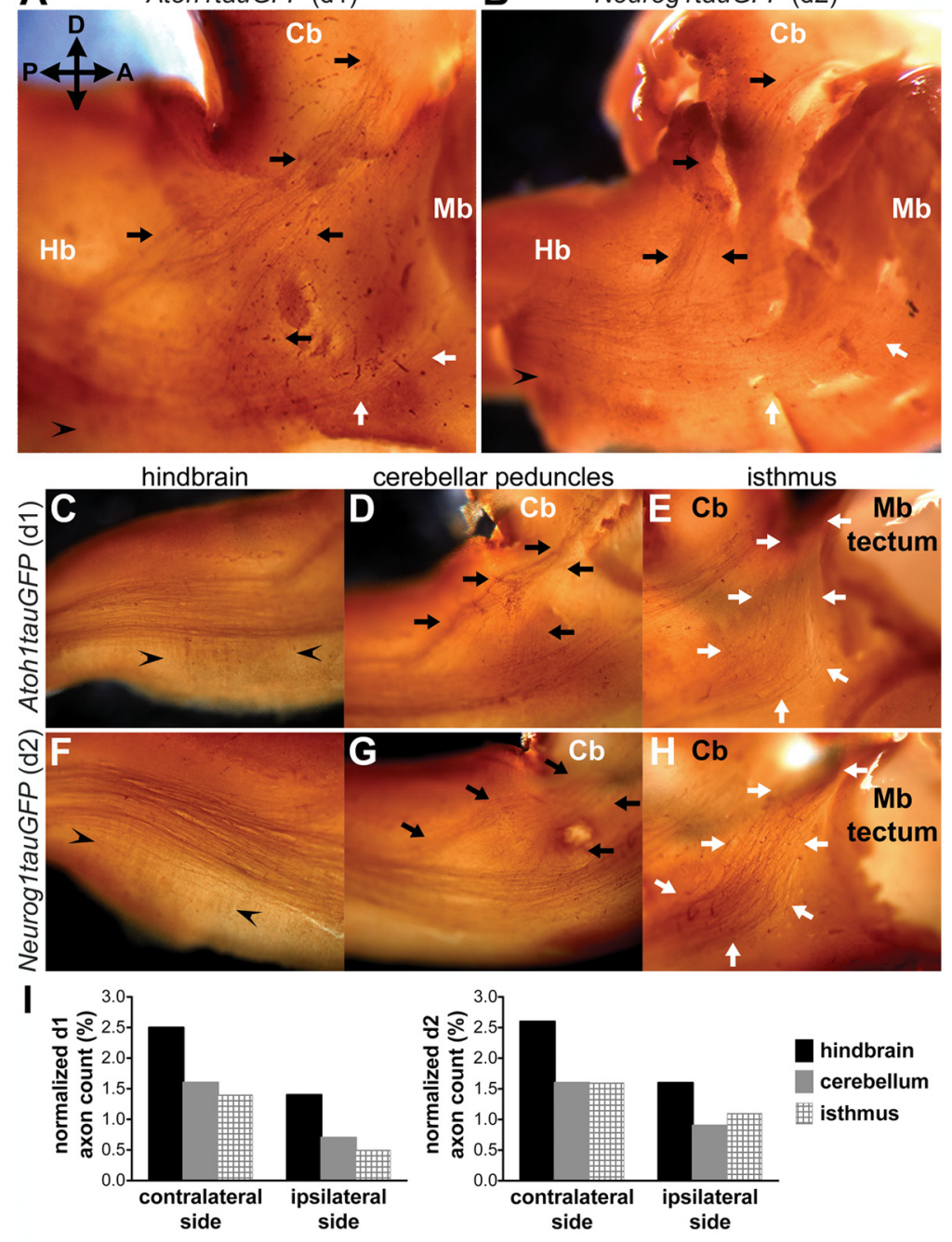

cerebellar peduncles
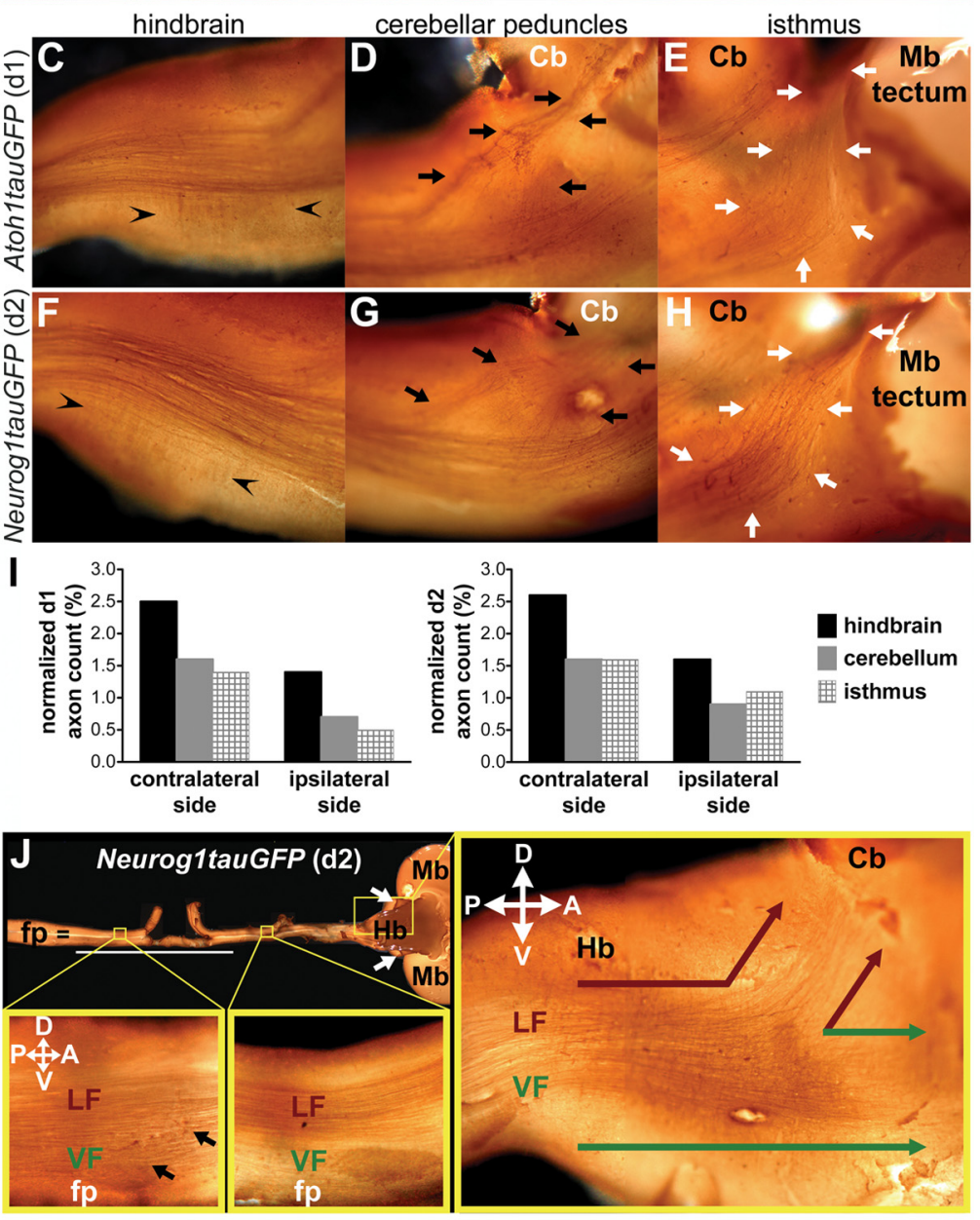

$\mathbf{K}$

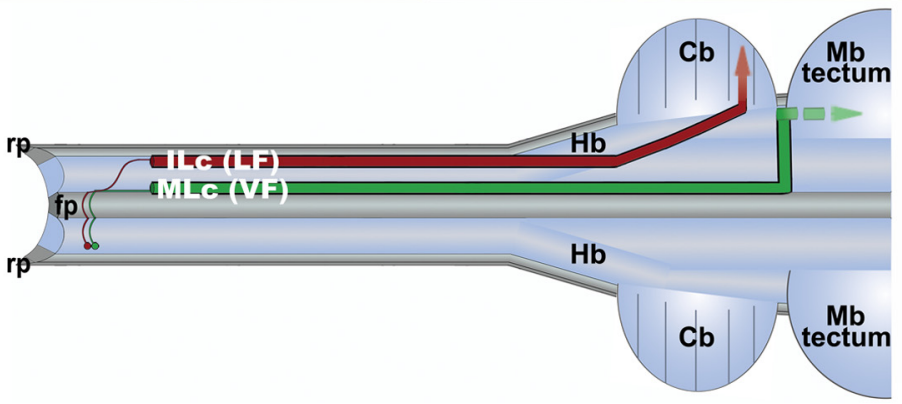

Figure 1. $\mathrm{d} 1$ and $\mathrm{d} 2$ axons project to the hindbrain, cerebellum, and isthmus in chick embryos. $\boldsymbol{A}, \boldsymbol{B}$, Lateral view of E10.5 (A) and E11.5 $(\boldsymbol{B})$ chick brain shows $\mathrm{d} 1(\boldsymbol{A})$ and d2 $(\boldsymbol{B})$ commissural axons projecting to the hindbrain $(\mathrm{Hb})$, the cerebellum ( $\mathrm{Cb}$; black arrows), and the isthmus (white arrows). Arrowheads in the hindbrain indicate the axons and/or collaterals, which make orthogonal turns and project ventrally. $\boldsymbol{C}-\boldsymbol{H}$, Lateral view of E11 chick brain shows d $1(\boldsymbol{C}-\boldsymbol{E})$ and d2 $(\boldsymbol{F}-\boldsymbol{H})$ commissural axons in the brain In the hindbrain $(\boldsymbol{C}, \boldsymbol{F})$, rostrally projecting and ventrally terminating (arrowheads) d1 $(\boldsymbol{C})$ and d2 $(\boldsymbol{F})$ commissural axons/
We quantified the NcadFL phenotype by analyzing the pathfinding defects displayed by $\mathrm{d} 2$ commissural axons in further detail. First, we confirmed that similar numbers of $\mathrm{d} 2$ commissural axons, normalized to the numbers of labeled cell bodies, crossed the floor plate (Fig. $3 \mathrm{~J}, \mathrm{~K}$, "crossing axons") in embryos electroporated with the reporter plasmids alone (control) and coelectroporated with the reporter and $c \beta a c t i n-N c a d F L$ plasmids (NcadFL; Fig. 3J). This confirmed that similar transfection efficiencies were achieved in control and experimental electroporations and revealed that $\mathrm{d} 2$ axons successfully crossed the floor plate following misexpression of NcadFL. We next quantified the postcrossing commissural axon phenotype resulting from the misexpression of NcadFL by determining the ratio of $\mathrm{d} 2$ ILc axons to decussated $\mathrm{d} 2$ axons. Consistent with our qualitative observations, the number of d2 ILc axons is significantly reduced in embryos electroporated with cßactinNcadFL, compared with control conditions (Fig. $3 \mathrm{~K}$ ). Collectively, our findings suggest that the hyperfasciculation of postcrossing MLc axons resulting from the misexpression of NcadFL prevents decussated commissural axons from projecting away from the floor plate along ILc trajectories and joining the LF.

\section{Loss of Ncad function alone does not perturb the pathfinding of postcrossing commissural axons}

Our findings raised the possibility that Ncad is normally required for the fascicu-

$\leftarrow$

collaterals are shown. d1 (D) and d2 (G) commissural axons form peduncles (black arrows) directed toward the cerebellum. White arrows indicate $\mathrm{d} 1(\boldsymbol{E})$ and $\mathrm{d} 2(\boldsymbol{H})$ commissural axons projecting to the isthmus. Midbrain $(\mathrm{Mb})$ tectum is removed for visual clarity. I, Quantification of d1 $(n=4)$ and $d 2$ ( $n=4)$ axons projecting in the hindbrain, the cerebellum, and isthmus on the contralateral and ipsilateral (electroporated) sides of the E10 chick brain. J, d2 axons in the ventral (top down) view of whole-mount E10 chick spinal cord and brain. Spinal cord is shown in open-book view. White line indicates the transfected area on the electroporated side. White arrows point to the two hemispheres of the cerebellum. In the spinal cord, the left boxed region locates at the thoracic level in the contralateral side, and the right box covers the cervical level. Black arrows indicate contralaterally projecting ILc axons. In the hindbrain, red arrows point to the axons within the LF that target the cerebellum, and green arrows point to the axons projecting to the isthmus from the VF. $\boldsymbol{K}$, Schematic of spinal commissural axon trajectories in open-book view of the spinal cord and brain. Red axons follow ILc trajectories contributing to the LF and projecting to the cerebellum. On the other hand, the green axons adopt an MLc trajectory, join the VF, and project to, and most likely beyond, the isthmus. fp, floor plate; rp, roof plate; $P$, posterior; $A$, anterior; $D$, dorsal; $V$, ventral. 

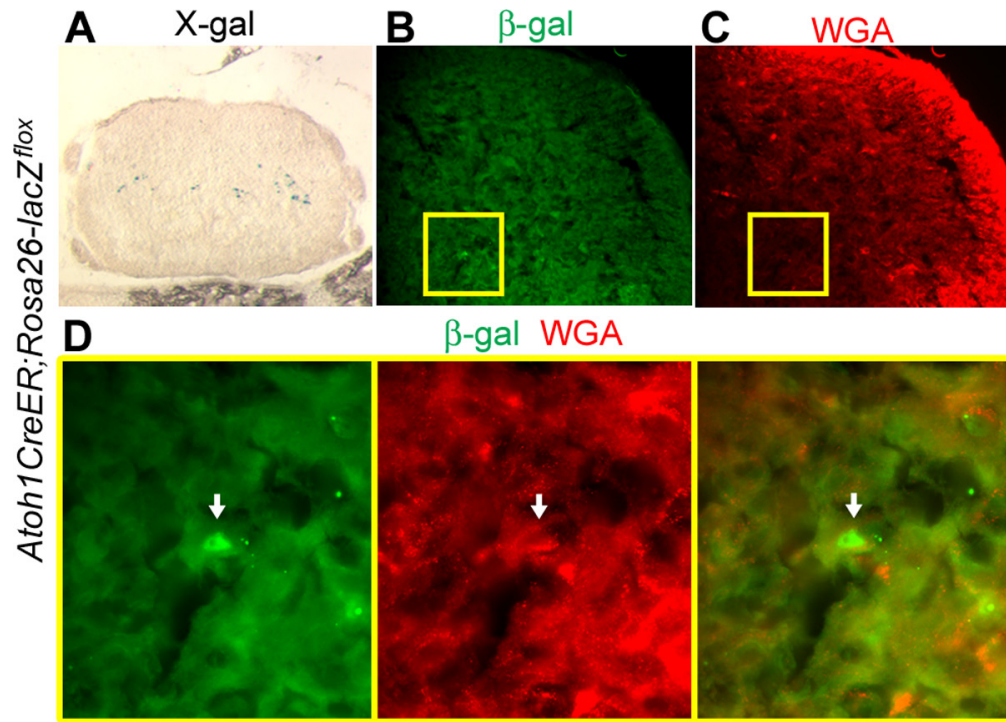

\section{$\beta$-gal WGA}
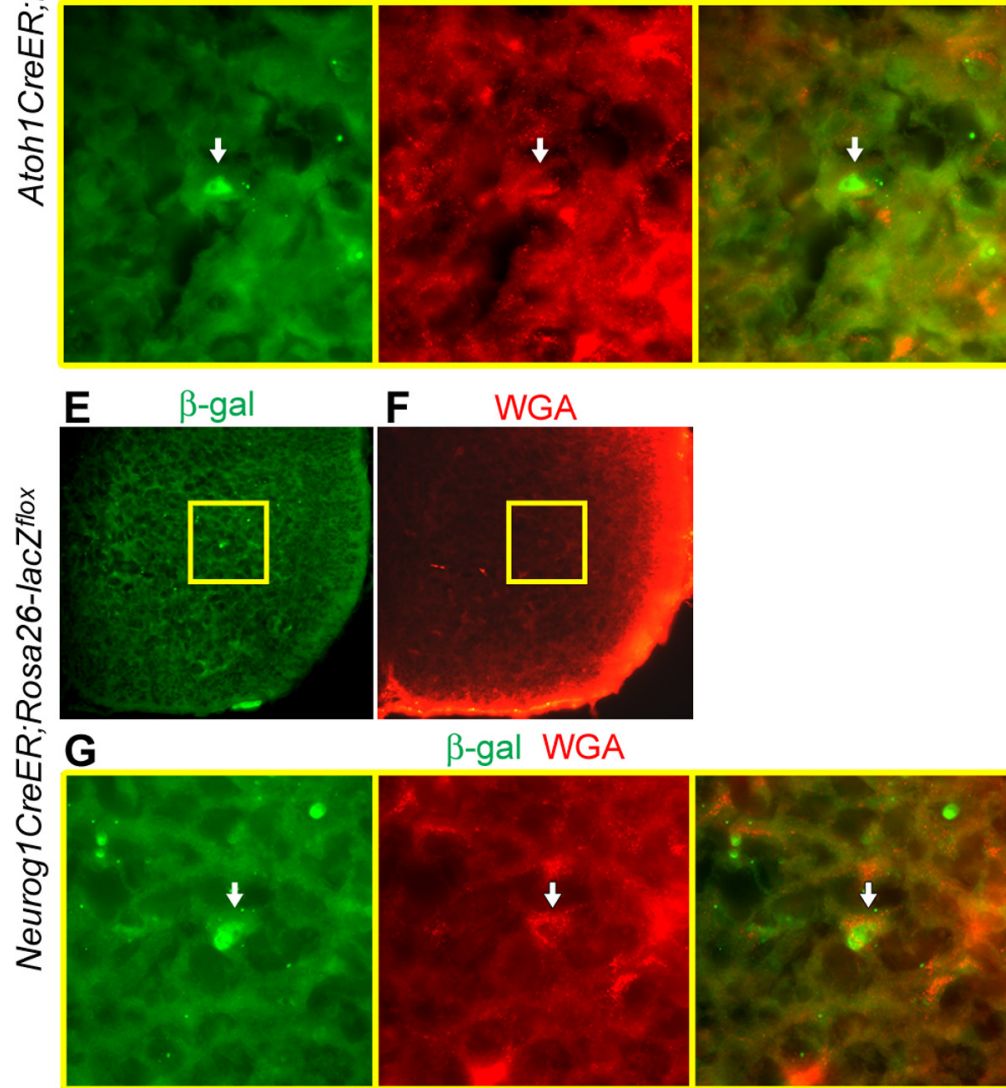

$\beta-g a l$ WGA
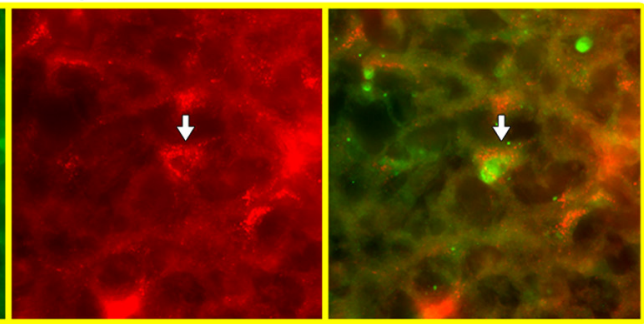

Figure 2. Retrograde tracing of spinocerebellar tract labels Atoh1 progenitor-derived d1 and Neurog1-lineage neurons in mouse spinal cord. A-D, P6 spinal cord of Atoh1CreER;Rosa26-Lac fllox mouse showing fate-mapped d1 cell bodies stained with $X$-gal $(\boldsymbol{A})$. Arrows identify the 11 cell body colabeled with $\beta$-gal and a retrograde tracer, Alexa Fluor 555 conjugate of WGA, which was injected into the cerebellum at $P 5(\boldsymbol{B}-\boldsymbol{D})$. $\boldsymbol{D}$, High-magnification views and merged image of boxed regions in $\boldsymbol{B}$ and $\boldsymbol{C}$. $\boldsymbol{E}-\boldsymbol{G}$, P6 spinal cord of Neurog1CreER;Rosa26-lac2 ${ }^{\text {flox }}$ mouse showing a Neurog1-derived cell body colabeled with WGA (see arrows). G, High-magnification views and merged image of boxed areas in $\boldsymbol{E}$ and $\boldsymbol{F}$.

lation of postcrossing MLc axons and, subsequently, VF formation. We tested this hypothesis by carrying out a variety of lossof-function manipulations. First, we used an MO to knock down Ncad protein expression and assessed the consequences of this manipulation on commissural axon pathfinding. Consistent with a previous report (Shiau and Bronner-Fraser, 2009), transfection of Ncad MO significantly reduced Ncad expression in the chick spinal cord (Fig. $4 A, B$ ). If Ncad-mediated fasciculation is required for the formation of MLc axon tracts, the loss of Ncad might be expected to result in a decrease in the number of MLc axons and a concomitant increase in the number of ILc axons. However, after transfecting E3-E3.5 chick spinal cord with the $\mathrm{Ncad} \mathrm{MO}$ and pan-axonal or $\mathrm{d} 2$ reporters we observed no obvious alterations in the numbers of ILc and MLc axons (Fig. 4C-F). In separate experiments, we found that electroporation of several different dominant-negative Ncad expression constructs capable of perturbing Ncad function (see below) also failed to disrupt the pathfinding of postcrossing commissural axons (data not shown). Together, these findings indicate that the loss of Ncad function alone does not interfere with the directed growth of postcrossing spinal commissural axons into the VF or LF.

\section{Simultaneous perturbation of Ncad and Robo function restores ILc axons and the contralateral lateral funiculus} Our findings to this point are consistent with a mechanism in which Robo normally inhibits $\mathrm{Ncad}$ function on postcrossing commissural axons and that this selectively facilitates the formation of the ILc axoncontaining LF. To provide further support for this model, we co-electroporated E3E3.5 chick embryo spinal cords with both $C A G-R o b o 1 \triangle C$-GFP and NcadMO and assessed the consequences of simultaneously perturbing Ncad and Robo function on the formation of postcrossing MLc and ILc axons. As revealed by the expression of GFP in open-book preparations derived from these embryos, interfering with both Robo-Slit signaling and Ncad partially rescued the dominant-negative Robo phenotype (Fig. $5 A, B)$. d2 ILc axons were also rescued to a similar extent in the absence of both Robo and Ncad function (Fig. 5C,D). Quantification of these phenotypes revealed a significant increase in the number of $\mathrm{d} 2$ ILc axons within spinal cords transfected with both $C A G-R o b o 1 \triangle C$-GFP and Ncad MO, as compared with those electroporated with the dominant-negative Robol construct and control MO (Fig. 5I).

Utilizing a complementary strategy to eliminate Ncad function we misexpressed a dominant-negative form of Ncad, $C A G$ $N c a d \Delta E$. This plasmid encodes an extracellular truncation of Ncad, which is incapable of interacting with NcadFL, but can bind downstream signaling molecules such as $\beta$-catenin via its cytoplasmic domain and, thus, represents a dominant-negative form of Ncad (Bozdagi et al., 2004). Consistent with the phenotype of chick embryos transfected with both CAG-Robo1 $\triangle C-G F P$ and NcadMO, co-electroporation of dominant-negative Robol and Ncad constructs partially rescued ILc projections (Fig. $5 E-H$ ). Together with the NcadFL overexpression phenotypes, these findings suggest that Robo-mediated inhibition of Ncad normally facilitates the formation of ILc axons and, consequently, the LF, by preventing the hyperfasciculation of postcrossing axons within the VF.

\section{Knockdown of Ncad via in utero electroporation in Ncad} conditional mutant mice rescues the Robo $\Delta \mathrm{C}$ perturbation To provide further support for Robo-mediated inhibition of Ncad function regulating contralateral commissural projections, and to determine whether this mechanism is conserved in mammals, we used in utero electroporation to ask whether interfering with Ncad 
A

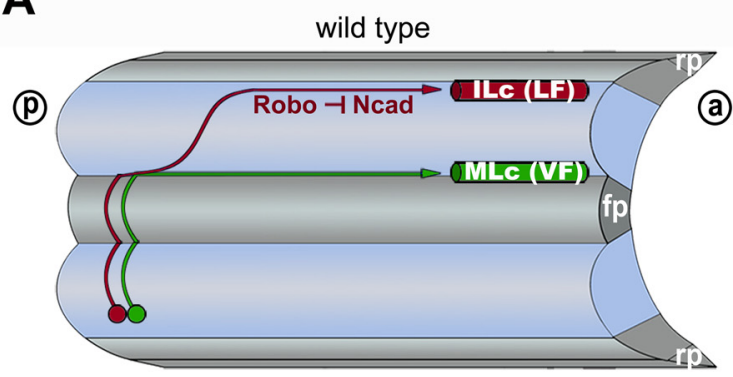

(P)

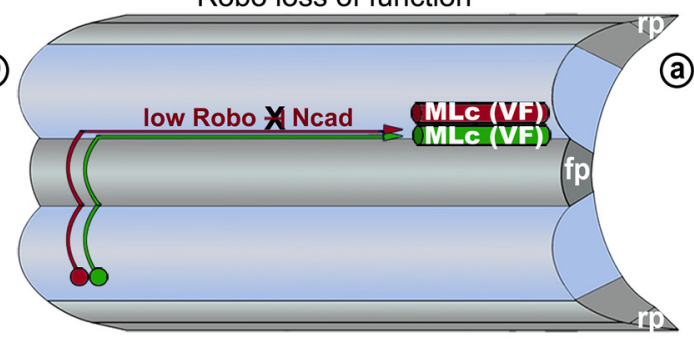

(a)
B
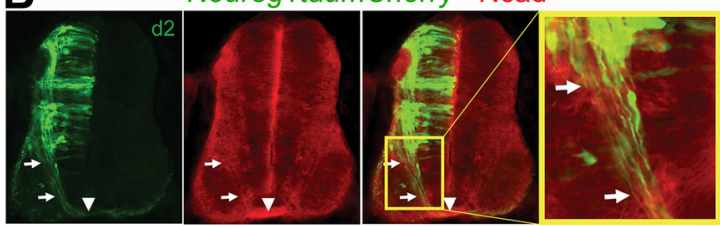

C ckactin-NcadFL CAG-tauGFP Ncad

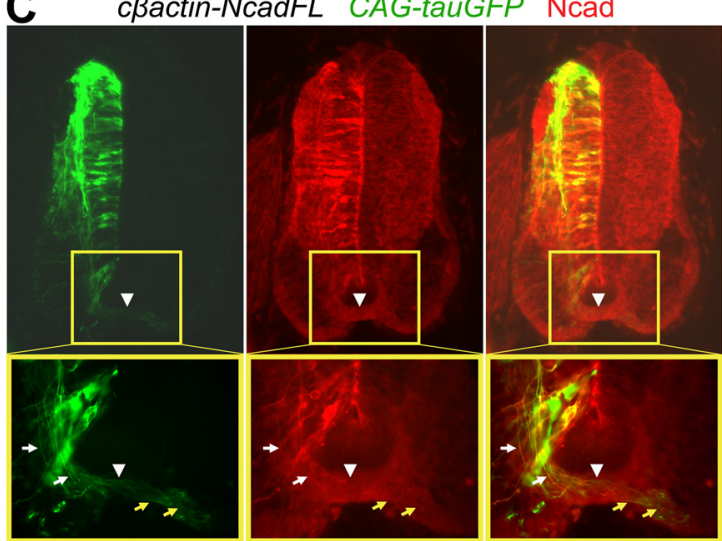

cßactin-NcadFL
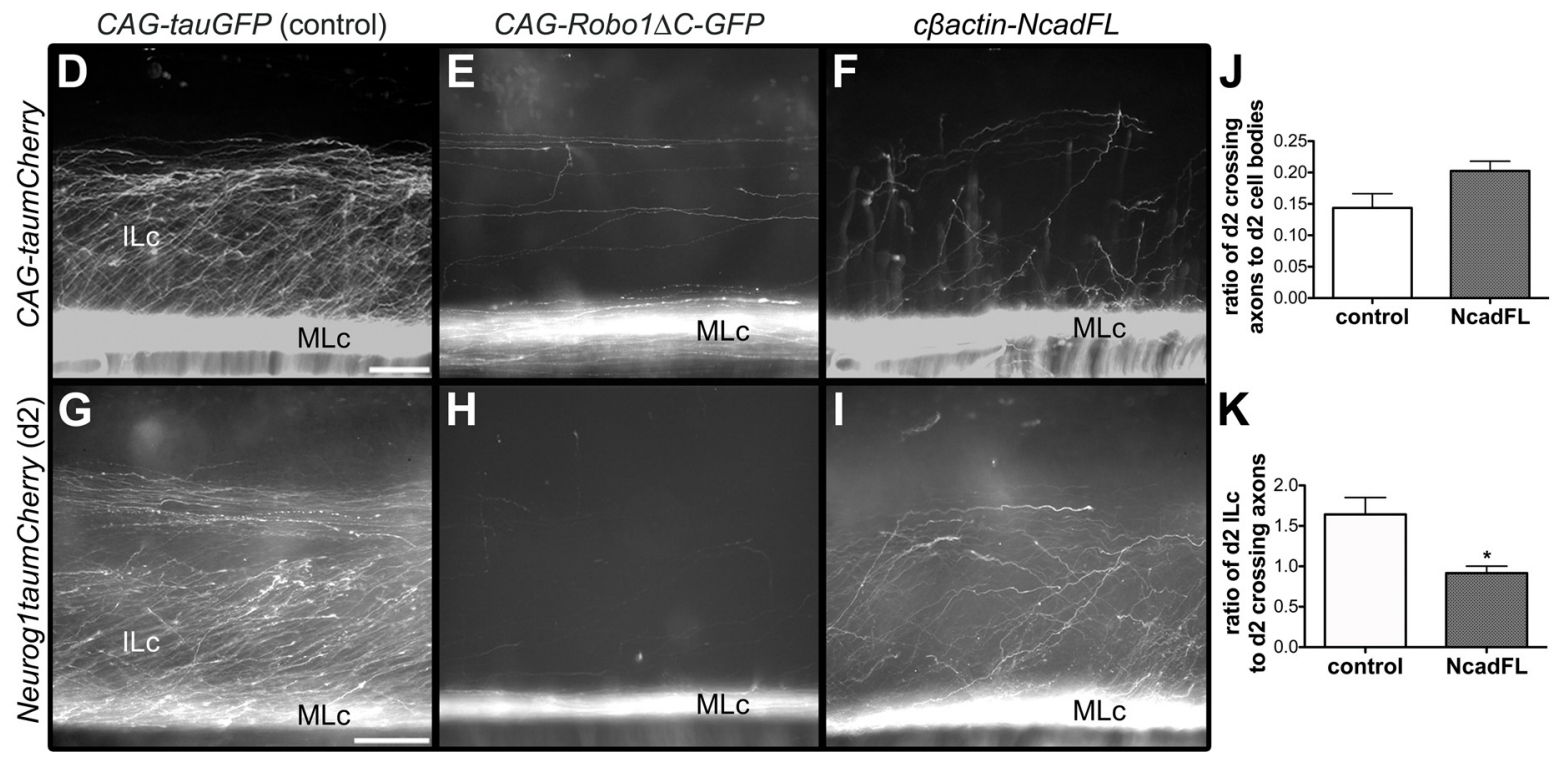

Figure 3. Misexpression of NcadFL on spinal commissural axons leads to a reduction in the number of ILcaxons. A, Schematic of commissural axon trajectories in open-bookview of the spinal cord unilaterally electroporated with reporter constructs. Axons from red and green neurons cross the floor plate (fp) and elaborate contralateral projections. In our model, Robo inhibition of $N$ cad directs red axon to elaborate an ILc trajectory and join the LF. Perturbing Robo function forces red axon to grow exclusively alongside the fp within the VF as a MLc projection. a, anterior; $p$, posterior; $r p$, roof plate. $\boldsymbol{B}$, Ncad expression on d2 commissural axons in E4.5 chick spinal cord. Arrows identify precrossing segments of commissural axons. Arrowheads point to the ventral commissure. $C$, Overexpression of NcadFL in E5 chick spinal cord following electroporation of $\_$Bactin-NcadFL and CAG-tauGFP constructs at E3. White arrows indicate misexpressed Ncad on precrossing, and yellow arrows point to postcrossing segments of GFP ${ }^{+}$commissural axons. Arrowheads identify the ventral commissure. $\boldsymbol{D}$-I, Decussated axons labeled with the pan-axonal marker CAG-taumCherry (D-F) or d2 marker NeurogltaumCherry (G-I) on the contralateral side of the electroporated embryo areshown in open-bookview. Compared with control embryos $(\mathbf{D}, \mathbf{G})$, misexpression of NcadFL results infewer ILcaxons and larger MLcbundles $(\boldsymbol{F}, \boldsymbol{I})$, phenocopying the effect of disabling Robo function $(\boldsymbol{E}, \boldsymbol{H})$ in $E 6$ chick spinal cord. Scale bars: $\boldsymbol{D}$ (for $\boldsymbol{D}-\boldsymbol{F}), \boldsymbol{G}$ (for $\mathbf{G}-\boldsymbol{I}), 100 \mu \mathrm{m}$.J, $\boldsymbol{K}$, Quantification of d2 ILc axon phenotype in wild-type and NcadFL-misexpressing embryos. The difference between normalized counts of d2 commissural axons in control $(n=5)$ and experiment $(n=5)$ conditions is not statistically significant, $(l)$ whereas normalized counts of d2 ILc axons misexpressing NcadFL are significantly reduced as compared with controls $\left(\boldsymbol{K},{ }^{*} p<0.05\right)$. All values show mean \pm SEM.

function rescues the dominant-negative Robo phenotype in the mouse spinal cord. Since Ncad homozygous-null mutant mice die by E10 (Radice et al., 1997), we electroporated floxed-Ncad $\left(N_{c a d}{ }^{f l o x}\right)$ mice (Kostetskii et al., 2005) with a Cre expression construct to selectively eliminate Ncad in the spinal cord of E11.5 homozygous embryos $\left(\mathrm{Ncad}^{f l / f l}\right)$. Just as we observed in the chick spinal cord, commissural axons transfected with the general reporter construct, CAG-tauGFP, and a control plasmid, CAG-IRES-GFP, which lacks a Cre sequence, elaborated both ILc and MLc trajectories in the $\mathrm{Ncad}^{f / f l}$ embryos (Fig. 6A), whereas, unilateral co-electroporation of
$\mathrm{Ncad}^{f l / f l}$ embryos with CAG-Robo1 $\triangle C$-GFP and CAG-IRES-GFP prevented the formation of ILc axons (Fig. $6 B$ ). On the other hand, coelectroporation of CAG-Robo1 $\triangle C$-GFP and CAG-nlsCre-IRES-GFP, which encodes a Cre sequence with a nuclear localization signal, in $N_{c a d} d^{f / f l}$ embryos, rescued the dominant-negative Robo phenotype and resulted in the formation of wild-type-like ILc axons (Fig. $6 C, D)$. These findings provide further support for Robo-mediated inhibition of Ncad regulating the positioning of longitudinal spinal axon tracts and indicate that this mechanism is conserved in mammals. 

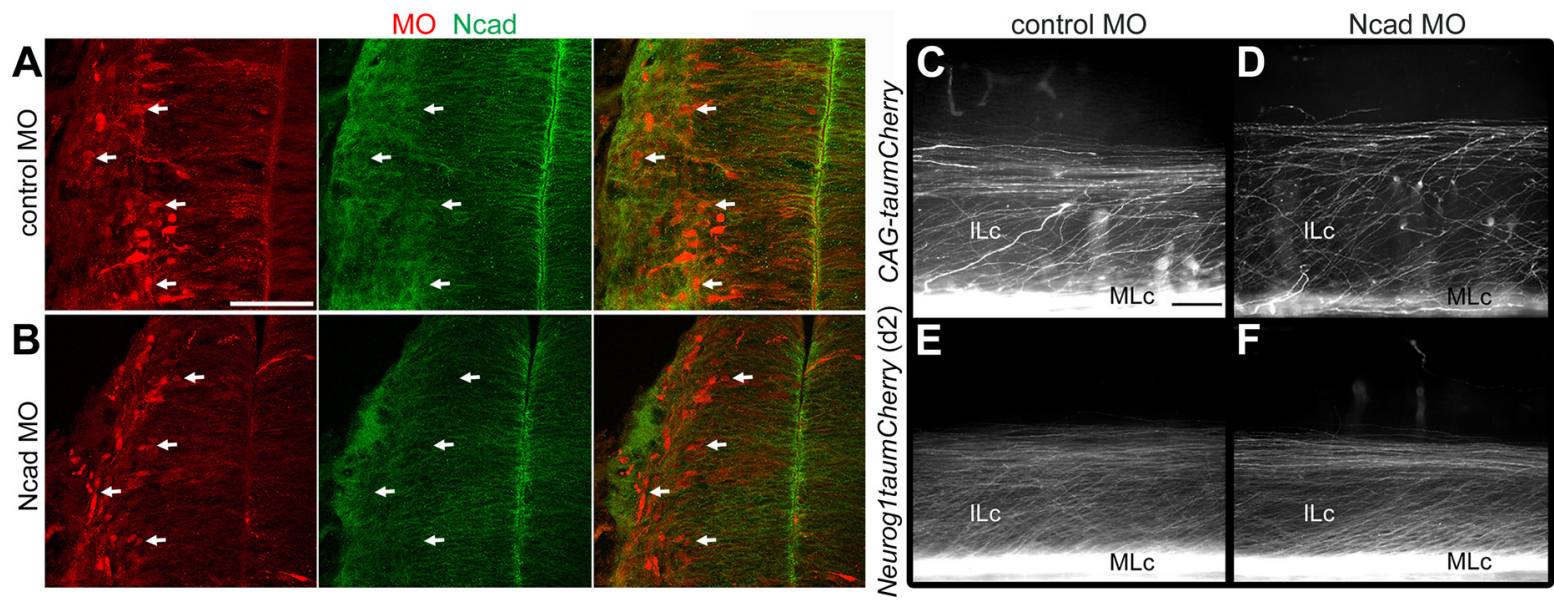

Figure 4. Knockdown of Ncad alone does not perturb the postcrossing trajectories of spinal commissural axons. $A, B$, Ncad expression in the $E 5$ chick spinal cord is reduced (see arrows) after transfection of $3^{\prime}$-lissamine-tagged Ncad MO $(\boldsymbol{B})$, as compared with embryos transfected with control MO $(\boldsymbol{A})$. Scale bar, $50 \mu \mathrm{m}$. $\mathbf{C}-\boldsymbol{F}$, Ncad knockdown $(\boldsymbol{D}, \boldsymbol{F})$ results in normal ILc and MLc projections, similar to controls $(\boldsymbol{C}, \boldsymbol{E})$, as shown by axons labeled with the pan-axonal $(\boldsymbol{C}, \boldsymbol{D})$ or d2 axon $(\boldsymbol{E}, \boldsymbol{F})$ reporters in E6 chick spinal cord. Scale bar, $100 \mu \mathrm{m}$.

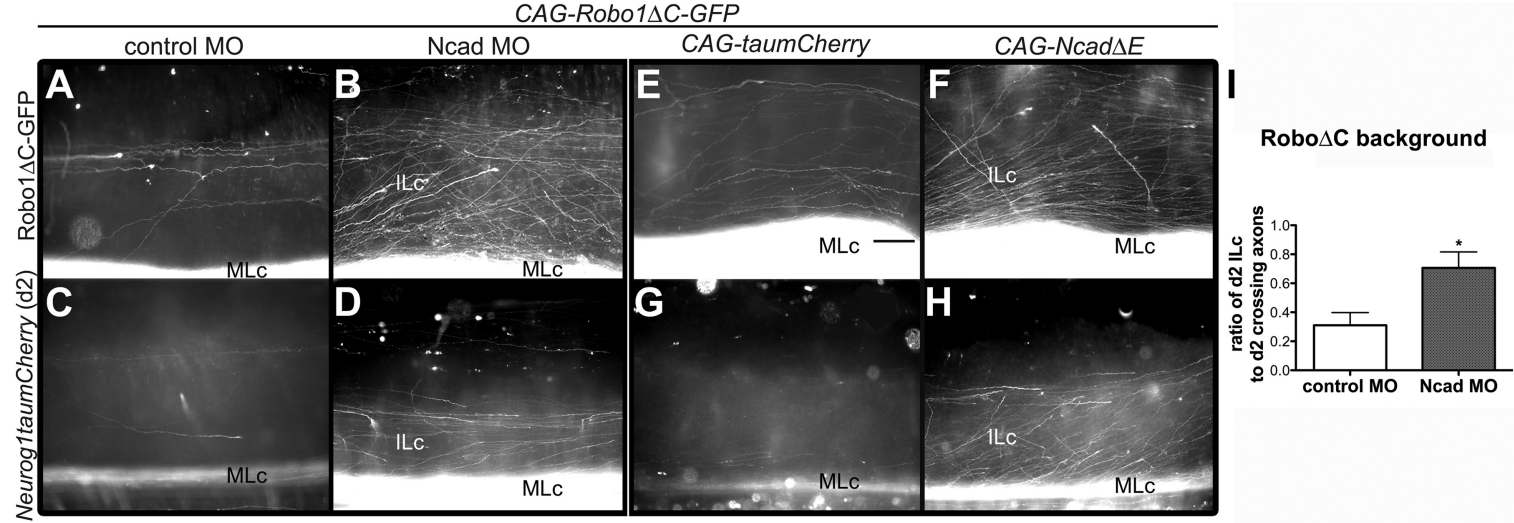

Figure 5. Knockdown of Ncad or mis-expression of a dominant-negative form of Ncad partially rescues the Robo $\Delta$ C phenotype. $A-D$, Cotransfection of E3-E3.5 chick spinal cord with Ncad MO and CAG-Robo1 $\triangle C$-GFP $(\boldsymbol{B}, \boldsymbol{D})$ restores ILc projections compared with controls $(\boldsymbol{A}, \boldsymbol{C})$ at E6, as shown by GFP-tagged Robo1 $\Delta$ C-expressing axons $(\boldsymbol{A}, \boldsymbol{B})$ and d2 axons $(\boldsymbol{C}, \boldsymbol{D})$. $\boldsymbol{E}-\boldsymbol{H}$, Electroporation of E3-E3.5 chick spinal cord with CAG-Ncad $\triangle E$ and CAG-Robo1 $\Delta C-G F P(\boldsymbol{F}, \boldsymbol{H})$ also results in the rescue of Robo $\Delta$ ( phenotype in E6 embryos, compared with control conditions $(\boldsymbol{E}, \boldsymbol{G})$. Axons are labeled with Robo $\Delta C-G F P(E, F)$ or d2 reporter $(\boldsymbol{G}, \boldsymbol{H})$ constructs. Scale bar, $100 \mu \mathrm{m}$. $\boldsymbol{I}$, The normalized counts of d2 ILc axons are significantly increased (mean \pm SEM, ${ }^{*} p<0.05$ ) in chick spinal cords transfected with Ncad M0 and CAG-Robo1 $\triangle$ C-GFP $(n=3)$ compared with the control $(n=3)$.
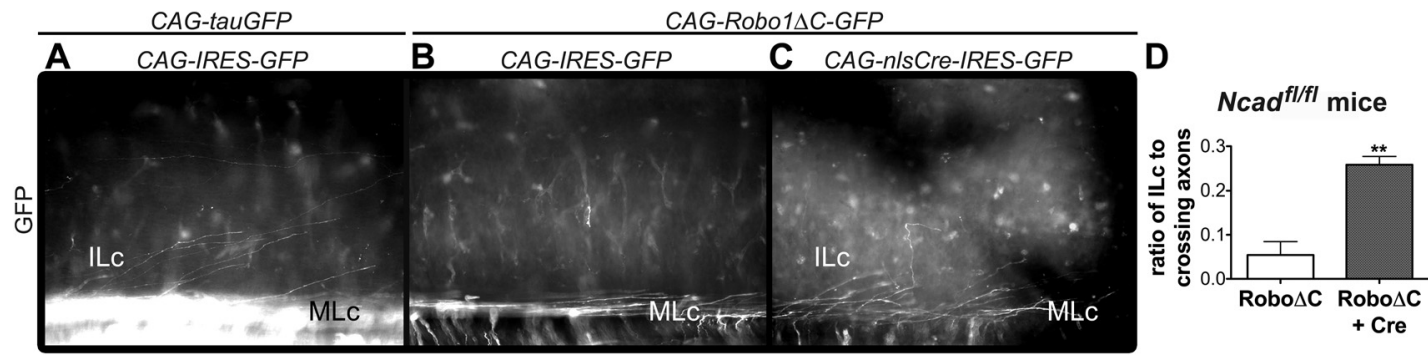

Figure 6. Ncad knockdown restores ILc trajectory in Ncad ${ }^{f / f t}$ mice. $A-C$, E13.5 open-book preparations from Ncad ${ }^{f / f l}$ mice spinal cord electroporated in utero at E11.5 show ILc and MLc projections of spinal commissural axons expressing reporter constructs only $(\boldsymbol{A})$, a reduction in ILc axons following misexpression of Robo $\Delta C(\boldsymbol{B})$, and the rescue of ILc axons expressing Robo $\Delta C$ and $(r e(C)$. $\boldsymbol{D}$, Significant increase in ILc axons (mean \pm SEM, $\left.{ }^{* *} p<0.005\right)$ within Ncad ${ }^{f / f t}$ spinal cord electroporated with CAG-Robo1 $\Delta C-G F P$ and CAG-nlsCre-IRES-GFP $(n=3)$, as compared with Ncad ${ }^{f / f f}$ spinal cord transfected with CAG-Robo1 $\triangle$ C-GFP and control plasmids $(n=3)$.

\section{Robo function or inhibition of Ncad-mediated adhesion is} required for the targeting of spinocerebellar axons in the brain

Given that spinal commissural axons project to multiple brain regions, including the cerebellum, we asked whether the positioning of these axons in distinct longitudinal tracts within the spinal cord marginal zone is required for their proper brain tar- geting. Since disabling Robo-Slit signaling results in the loss of ILc axons, and the commissural axon-containing portion of the LF (Fig. $3 E, H$ ), we exploited this manipulation to selectively ask whether mis-sorted decussated spinal commissural axons project to their appropriate brain targets. For these analyses, we used a general axon reporter construct CAG-GPI-AP (Arakawa et al., 2008), which expresses GPI-anchored human placental AP, to 

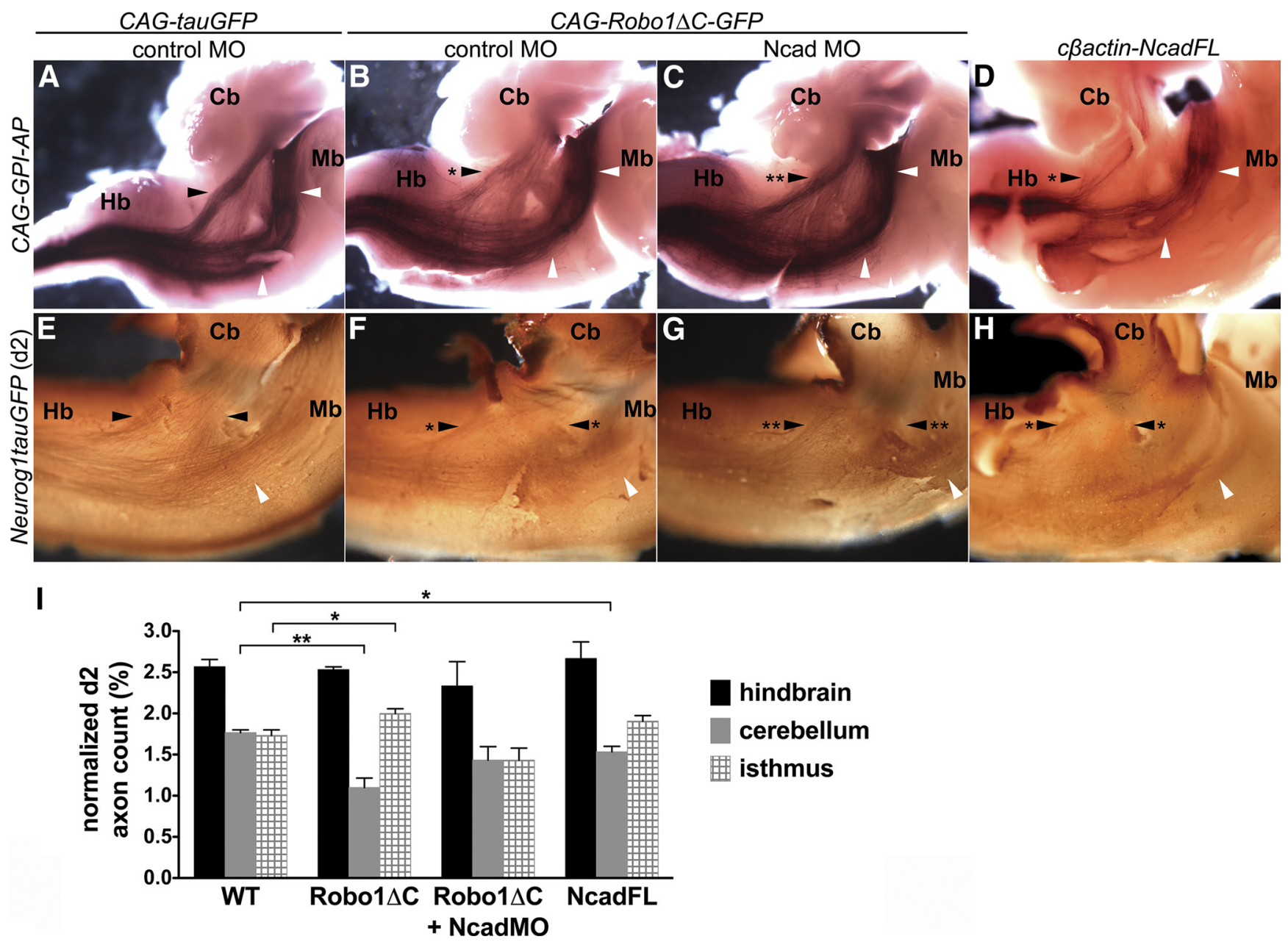

hindbrain

cerebellum

困 isthmus

Figure 7. Spinal commissural axons expressing Robo1 $\Delta$ Cor NcadFL fail to project to the cerebellum and mis-project to the isthmus, and perturbation of Ncad rescues this phenotype. A-D, Spinal commissural axons on the contralateral side of E13 whole-mount chick brain following transfection of E3-E3.5 spinal cord with respective constructs and M0. As compared with wild-type embryos (A), the contralateral spinocerebellar tract (black arrowhead with asterisk) is reduced in embryos electroporated with CAG-Robo1 $\triangle$ C-GFP and control M0, whereas the projection of axons to the isthmus (white arrowheads) is increased (B). Simultaneous perturbation of Robo and Ncad function restores the projection of spinal commissural axons to the cerebellum (Cb; indicated by two asterisks in (C). A subset of spinal commissural axons misexpressing NcadFL also fails to project to the cerebellum (D). $\boldsymbol{E}-\boldsymbol{H}, \operatorname{In} E 10$ chick brain, there is also a reduction in the projection of Robo1 $\Delta \boldsymbol{C}$ or NcadFL-expressing d2 commissural axons to the cerebellum (asterisk in $\boldsymbol{F}, \boldsymbol{H})$ compared with the control (E). Cotransfection of CAG-Robo1 $\Delta C$-GFP and Ncad M0 in the E3 chick spinal cord restores the d2 spinocerebellar tract (two asterisks in G). I, Normalized d2 axon counts in the hindbrain, the cerebellum, and the isthmus indicate a significant reduction $\left({ }^{* *} p<0.01\right)$ in the spinocerebellar tract and a significant increase in projection to the isthmus $\left({ }^{*} p<0.05\right)$ formed by d2 commissural axons following transfection with CAG-Robo1 $\Delta C-G F P$ and control M0 (Robo1 $\Delta C ; n=3$ ), compared with the control (wild-type, WT; $n=3$ ). Normalized axon counts of d2 commissural axons misexpressing NcadFL (NcadFL; $n=3$ ) are also significantly reduced in the cerebellum, compared with the control ( ${ }^{*} p<0.05$ ). There is no statistically significant difference between normalized d 2 commissural axon counts in WT embryos and those transfected with Robo $1 \Delta C-G F P$ and $\mathrm{Ncad} \mathrm{MO}(\operatorname{Rob} 01 \Delta \mathrm{C}+\mathrm{NcadMO} ; n=3)$, indicating the rescue of projections to the cerebellum and isthmus. All values show mean $\pm \mathrm{SEM}$. $\mathrm{Hb}$, hindbrain; Mb, midbrain.

achieve robust colorimetric labeling of axons in a subset of embryos, and the $\mathrm{d} 2$ reporter construct for quantifying the targeting of labeled spinal commissural axons in a separate set of embryos. The brains of the embryos electroporated with the pan-axonal and $\mathrm{d} 2$-specific reporters were analyzed at E13 and E10, respectively, after co-electroporation of the E3-E3.5 chick spinal cord with either control CAG-tauGFP or CAG-Robol $\triangle C$-GFP constructs. The numbers of the transfected $\mathrm{d} 2$ cell bodies did not vary significantly between experiments: $3419 \pm 266.3$ for control, $3214 \pm 74.27$ for CAG-Robo1 $\Delta C$-GFP, $2509 \pm 191.5$ for CAGRobo1 $\triangle C$-GFP and NcadMO, and $3928 \pm 52.78$ for NcadFL ( $n=$ 3 for each experiment). Notably, the normalized counts of rostrally projecting axons in the hindbrain were similar in embryos electroporated with the control or CAG-Robo1 $\triangle C$-GFP constructs, indicating that spinal axons appropriately reached the hindbrain in the presence or absence of Robo signaling function (Fig. $7 A-C, E-G, I$ ). However, the number of commissural axons projecting to the cerebellum was significantly reduced in embryos transfected with the dominant-negative Robol construct, (Fig. $7 B, F, I$ ), compared with control embryos (Fig. $7 A, E, I$ ). On the other hand, the number of commissural axons projecting to the isthmus was significantly increased in the embryos transfected with CAG-Robo1 $\triangle C$-GFP (Fig. 7 B, F,I). Further consistent with Robo-mediated inhibition of Ncad regulating the targeting of spinal projection neurons, simultaneously perturbing Robo and Ncad function rescued the contralateral spinocerebellar tract (Fig. 7C,G,I). Importantly, a subset of spinal commissural axons that overexpress NcadFL also fail to project to the cerebellum (Fig. $7 D, H, I$ ).

Together, these results suggest that Robo-mediated inhibition of Ncad adhesion is required for the proper positioning of postcrossing spinal commissural axons within the LF of the spinal cord marginal zone and, in turn, for their targeting to the cerebellum (Fig. 8). 


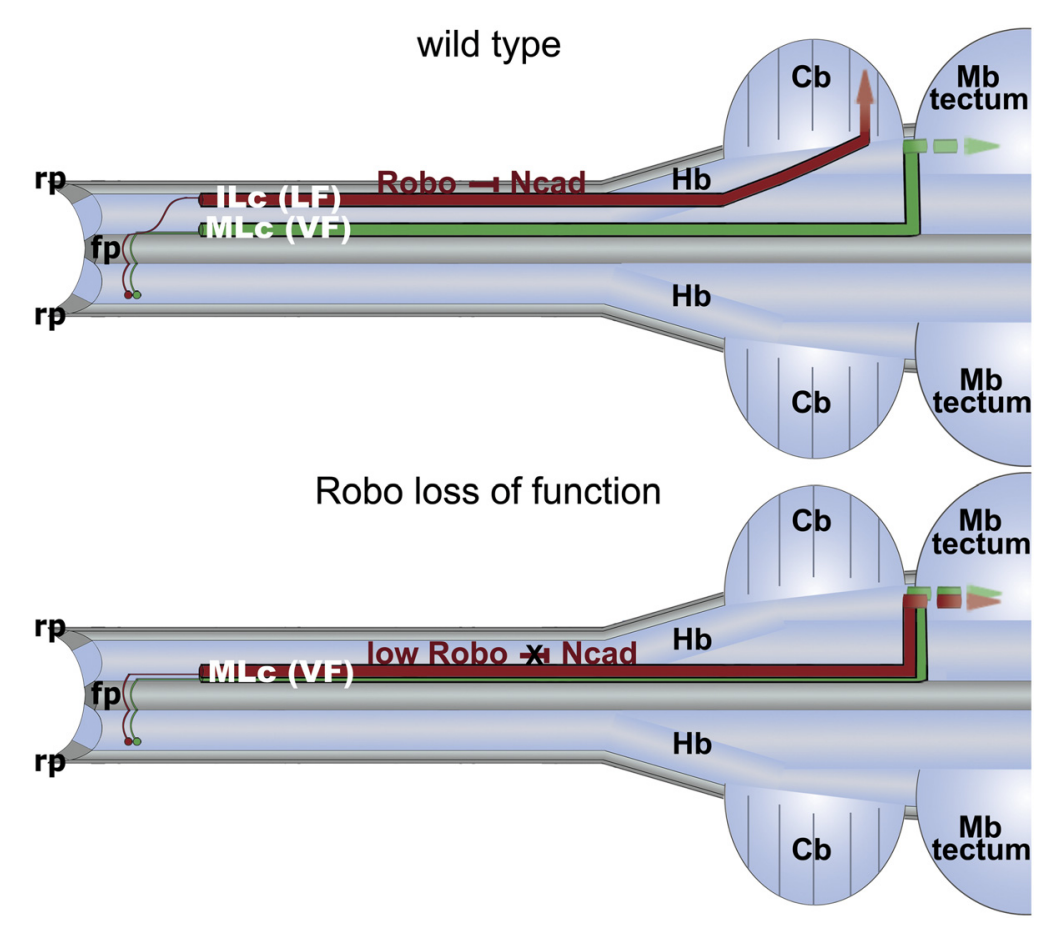

Figure 8. Sorting of postcrossing commissural axons via Robo-mediated inhibition of Ncad is required for spinocerebellar tract formation. Schematic of spinal commissural axon trajectories in open-book view of the spinal cord and brain. In wild-type embryos, Robo inhibition of Ncad directs red axons along an ILc trajectory, so that they can join the LF and project to the cerebellum (Cb). On the other hand, the green axons join the VF by adopting an MLc trajectory and project to, and most likely beyond, the isthmus. As a consequence of perturbing Robo function (Robo loss of function), red axons inappropriately elaborate MLc projections that grow exclusively alongside the floor plate ( $\mathrm{fp}$ ) within the VF and which, in turn, mis-project to the isthmus. rp, roof plate; $\mathrm{Hb}$, hindbrain; $\mathrm{Mb}$, midbrain.

\section{Discussion}

Here, we describe, for the first time, a molecular mechanism that controls the directed growth of spinal axons to brain targets. According to our model, the axons of spinal commissural projection neurons are presorted into distinct longitudinal funiculi within the marginal zone, via Robo-mediated inhibition of Ncad, and this facilitates their projection to appropriate brain targets (Fig. 8).

\section{$\mathrm{d} 1$ and $\mathrm{d} 2$ projection neurons target multiple brain regions}

Anatomical and physiological studies in vertebrates have correlated the positions of funiculi within the spinal cord marginal zone with the particular brain regions that their component axons ultimately target (Brodal, 1998; Willis, 2007; Sakai and Kaprielian, 2012). In particular, the spinocerebellar tract is the only major ascending projection in the dorsal LF that targets the brain (Brodal, 1998; Xu and Grant, 2005; Willis, 2007). The ventral LF harbors additional components of the spinocerebellar tract and a portion of the anterolateral system, and the VF contains the remaining portion of the anterolateral system and the spino-olivary tract (Kerr, 1975; Giesler Jr. et al., 1981; Richmond et al., 1982; Brodal, 1998; Xu and Grant, 2005; Willis, 2007). The spatial organization of longitudinal tracts within the marginal zone revealed by these studies suggests that spinal projection neurons (including $\mathrm{d} 1$ and $\mathrm{d} 2$ ) whose axons contribute to the LF and VF, connect to multiple brain regions, and that spinal ascending axons, which join the dorsal LF, project to the cerebellum. However, the brain targets of specific subtypes of projection neurons have yet to be explicitly identified.

In the chick spinal cord, it has previously been shown that both $\mathrm{d} 1$ and $\mathrm{d} 2$ commissural neurons extend postcrossing ILc and MLc axons into the LF and VF, respectively (Reeber et al., 2008; Avraham et al., 2009). We show here that, consistent with the known anatomy and physiology of spinal projection neurons, $\mathrm{d} 1$ and $\mathrm{d} 2$ axons project to multiple brain regions, and that a significant subset of both populations targets the cerebellum. This latter observation is consistent with the results of our retrograde labeling experiments performed in Atoh1 and Neurog1 reporter mice, as well as with the findings of an independent dye-tracing study suggesting that Atoh1 progenitor-derived d1 neurons/axons contribute to the spinocerebellar tract (Bermingham et al., 2001). In addition, we show for the first time that $\mathrm{d} 1$ and $\mathrm{d} 2$ axons also contribute to other major ascending tracts, which project to the brain. For example, some $\mathrm{d} 1$ and $\mathrm{d} 2$ axons and/or their collaterals in the hindbrain execute ventrally directed orthogonal turns, identifying them as likely components of spino-olivary and spinoreticular tracts (Kerr, 1975; Brodal, 1998). The remaining sets of labeled axons appear to be destined for the cerebellum or more rostrally located targets. However, we were unable to follow these particular axons beyond the isthmus, even using a pan-axonal reporter that provides more robust labeling of these projections. This is most likely due to the fact that after reaching the isthmus ascending spinal axons, which contribute to the anterolateral system, are no longer visible as they invade deep interior regions of the midbrain (Kerr, 1975; Björkeland and Boivie, 1984; Brodal, 1998).

\section{A critical role for axon sorting regulated by Robo-mediated inhibition of Ncad-dependent fasciculation in spinocerebellar tract formation}

Although it is well established that ascending longitudinal axons are positioned within distinct funiculi in the spinal cord marginal zone, whether this organizational pattern is required for the longrange guidance and targeting of these axons has not been addressed. Our findings suggest that ascending projection neuron axons must be presorted within the spinal cord proper to project to their appropriate brain targets. Similarly, olfactory sensory axons are spatially arranged according to their target sites in the olfactory bulb and this topographic organization is, in part, regulated by the molecular identities of individual olfactory sensory neurons, the expression of distinct olfactory receptors, and, ultimately, by axon-associated expression gradients of canonical guidance cues such as Semaphorins and Neuropilins (Sakano, 2010). Notably, presorting of olfactory sensory axons, as opposed to target-derived guidance cues, regulates the targeting of these axons within the olfactory bulb (Imai et al., 2009).

Analogous to the mechanisms underlying axon targeting in the olfactory system, we propose that Robo inhibition of Ncad function sorts decussated spinal commissural axons into the LF within the spinal cord marginal zone, and that this is required for their correct projection to the cerebellum. Our findings suggest that the high levels of Robo likely expressed on ILc axons inhibit Ncad-dependent fasciculation, allowing these axons to break 
away from the VF and join the LF. In support of this model, simultaneous perturbation of Robo and Ncad function in the spinal cord partially rescues the formation of not only the contralateral LF, but also the spinocerebellar tract. Although it is certainly possible that Robo and Ncad regulate the formation of ILc axons and the LF through distinct parallel signaling pathways, we favor our model since disabling Robo function has been demonstrated to eliminate virtually all ILc axons (Long et al., 2004; Reeber et al., 2008; Jaworski et al., 2010) (Figs. 3, 5, 6). Moreover, elegant biochemical studies have shown that Slit-activation of Robo inhibits Ncad-mediated adhesion in vitro (Rhee et al., 2002, 2007), and Robo-Slit signaling facilitates retinal ganglion cell development by attenuating Ncad activity in zebrafish (Wong et al., 2012).

Consistent with the Robo-Ncad model we propose, VF formation, likely driven by the fasciculation of MLc axons, might also be dependent on Ncad function. Accordingly, the selective disruption of Ncad could result in a defasciculation of MLc axon bundles, effectively reducing the thickness of the VF. However, we show that introducing Ncad MOs into, or misexpressing a dominant-negative Ncad construct in, the embryonic chick spinal cord does not significantly perturb the pathfinding of postcrossing commissural axons. Whereas the lack of an axon-sorting phenotype in these experiments could reflect an incomplete or insufficient disruption of $\mathrm{Ncad}$ function, it is also possible that Ncad is specifically expressed on the ILc subset of postcrossing commissural axons and not required for the directed growth of MLc axons. However, it would be difficult to visualize such an axon subtype-specific expression pattern since ILc axons must project through the VF to reach the LF. Alternatively, Ncad may have a permissive role in longitudinal axon guidance and tract formation. In this case, the consequences of disrupting Ncad may only be discernible in the absence of Robo function. Since axon fasciculation and outgrowth generally require the concerted actions of a variety of cell adhesion molecules (Van Vactor, 1998; Raper and Mason, 2010), the selective elimination of Ncad function might not be expected to result in a clear phenotype. Potentially relevant to either scenario, it is interesting to note that the spinal cord of mouse embryos lacking the atypical cadherin, Celsr3, which is the mammalian homolog of Drosophila Flamingo, exhibit an abnormally thick LF and a thinner VF. Moreover, the spinocerebellar tract, which travels within the dorsal LF, in the hindbrain is also enlarged in Celsr3 mutants (Tissir et al., 2005). These phenotypes suggest that Celsr3 has a key role in sorting spinal projection neuron axons along MLc trajectories within the VF and their proper projection to brain targets, most likely to and beyond the isthmus.

Notably, Ncad expression levels on ascending axons within ventrolateral funiculi in the chick spinal cord begin to decrease at E6 and are extinguished at E7 when spinocerebellar tracts reach the brain (Redies et al., 1992). As opposed to a direct role for Robo-Ncad interactions in the targeting of longitudinal tracts to the brain, this observation supports our contention that Robomediated inhibition of Ncad in the spinal cord proper regulates the formation of the LF, which in turn facilitates spinocerebellar tract formation. Although we favor the view that sorting projection of these axons to the brain, target-derived cues may also have a role in this process. It is interesting to note in this regard that Slits are present in the chick hindbrain and cerebellum when spinocerebellar tracts enter the brain (Gilthorpe et al., 2002). Whether or not these brain-derived Slits are also required for spinocerebellar tract formation remains an untested and open question.

\section{References}

Arakawa T, Iwashita M, Matsuzaki F, Suzuki T, Yamamoto T (2008) Paths, elongation, and projections of ascending chick embryonic spinal commissural neurons after crossing the floor plate. Brain Res 1223:25-33. CrossRef Medline

Avraham O, Hadas Y, Vald L, Zisman S, Schejter A, Visel A, Klar A (2009) Transcriptional control of axonal guidance and sorting in dorsal interneurons by the Lim-HD proteins Lhx9 and Lhx1. Neural Dev 4:21. CrossRef Medline

Bermingham NA, Hassan BA, Wang VY, Fernandez M, Banfi S, Bellen HJ, Fritzsch B, Zoghbi HY (2001) Proprioceptor pathway development is dependent on MATH1. Neuron 30:411-422. CrossRef Medline

Björkeland M, Boivie J (1984) The termination of spinomesencephalic fibers in cat. Anat Embryol 170:265-277. CrossRef Medline

Bovolenta P, Dodd J (1990) Guidance of commissural growth cones at the floor plate in embryonic rat spinal cord. Development 109:435-447. Medline

Bozdagi O, Valcin M, Poskanzer K, Tanaka H, Benson DL (2004) Temporally distinct demands for classic cadherins in synapse formation and maturation. Mol Cell Neurosci 27:509-521. CrossRef Medline

Brodal P (1998) The central nervous system: structure and function. New York: Oxford UP.

Bultje RS, Castaneda-Castellanos DR, Jan LY, Jan YN, Kriegstein AR, Shi SH (2009) Mammalian Par3 regulates progenitor cell asymmetric division via notch signaling in the developing neocortex. Neuron 63:189-202. CrossRef Medline

Garel S, Rubenstein JL (2004) Intermediate targets in formation of topographic projections: inputs from the thalamocortical system. Trends Neurosci 27:533-539. CrossRef Medline

Giesler GJ Jr, Spiel HR, Willis WD (1981) Organization of spinothalamic tract axons within the rat spinal cord. J Comp Neurol 195:243-252. CrossRef Medline

Gilthorpe JD, Papantoniou EK, Chédotal A, Lumsden A, Wingate RJ (2002) The migration of cerebellar rhombic lip derivatives. Development 129: 4719-4728. Medline

Hammond R, Vivancos V, Naeem A, Chilton J, Mambetisaeva E, Andrews W, Sundaresan V, Guthrie S (2005) Slit-mediated repulsion is a key regulator of motor axon pathfinding in the hindbrain. Development 132:44834495. CrossRef Medline

Imai T, Yamazaki T, Kobayakawa R, Kobayakawa K, Abe T, Suzuki M, Sakano H (2009) Pre-target axon sorting establishes the neural map topography. Science 325:585-590. CrossRef Medline

Imondi R, Kaprielian Z (2001) Commissural axon pathfinding on the contralateral side of the floor plate: a role for B-class ephrins in specifying the dorsoventral position of longitudinally projecting commissural axons. Development 128:4859-4871. Medline

Imondi R, Wideman C, Kaprielian Z (2000) Complementary expression of transmembrane ephrins and their receptors in the mouse spinal cord: a possible role in constraining the orientation of longitudinally projecting axons. Development 127:1397-1410. Medline

Iwai Y, Usui T, Hirano S, Steward R, Takeichi M, Uemura T (1997) Axon patterning requires DN-cadherin, a novel neuronal adhesion receptor, in the Drosophila embryonic CNS. Neuron 19:77-89. CrossRef Medline

Jaworski A, Long H, Tessier-Lavigne M (2010) Collaborative and specialized functions of Robo1 and Robo 2 in spinal commissural axon guidance. J Neurosci 30:9445-9453. Medline

Jevince AR, Kadison SR, Pittman AJ, Chien CB, Kaprielian Z (2006) Distribution of EphB receptors and ephrin-B1 in the developing vertebrate spinal cord. J Comp Neurol 497:734-750. CrossRef Medline

Kadison SR, Kaprielian Z (2004) Diversity of contralateral commissural projections in the embryonic rodent spinal cord. J Comp Neurol 472:411422. CrossRef Medline

Kerr FW (1975) The ventral spinothalamic tract and other ascending systems of the ventral funiculus of the spinal cord. J Comp Neurol 159:335356. CrossRef Medline

Kostetskii I, Li J, Xiong Y, Zhou R, Ferrari VA, Patel VV, Molkentin JD, Radice GL (2005) Induced deletion of the N-cadherin gene in the heart leads to dissolution of the intercalated disc structure. Circ Res 96:346354. CrossRef Medline

Koundakjian EJ, Appler JL, Goodrich LV (2007) Auditory neurons make stereotyped wiring decisions before maturation of their targets. JNeurosci 27:14078-14088. CrossRef Medline 
Krull CE (2004) A primer on using in ovo electroporation to analyze gene function. Dev Dyn 229:433-439. CrossRef Medline

Long H, Sabatier C, Ma L, Plump A, Yuan W, Ornitz DM, Tamada A, Murakami F, Goodman CS, Tessier-Lavigne M (2004) Conserved roles for slit and robo proteins in midline commissural axon guidance. Neuron 42:213-223. CrossRef Medline

Lumpkin EA, Collisson T, Parab P, Omer-Abdalla A, Haeberle H, Chen P, Doetzlhofer A, White P, Groves A, Segil N, Johnson JE (2003) Math1driven GFP expression in the developing nervous system of transgenic mice. Gene Expr Patterns 3:389-395. CrossRef Medline

Luo L, Flanagan JG (2007) Development of continuous and discrete neural maps. Neuron 56:284-300. CrossRef Medline

Machold R, Fishell G (2005) Math1 is expressed in temporally discrete pools of cerebellar rhombic-lip neural progenitors. Neuron 48:17-24. CrossRef Medline

Nakada Y, Parab P, Simmons A, Omer-Abdalla A, Johnson JE (2004) Separable enhancer sequences regulate the expression of the neural bHLH transcription factor neurogenin 1. Dev Biol 271:479-487. CrossRef Medline

Niwa H, Yamamura K, Miyazaki J (1991) Efficient selection for highexpression transfectants with a novel eukaryotic vector. Gene 108:193199. CrossRef Medline

Radice GL, Rayburn H, Matsunami H, Knudsen KA, Takeichi M, Hynes RO (1997) Developmental defects in mouse embryos lacking N-cadherin. Dev Biol 181:64-78. CrossRef Medline

Raper J, Mason C (2010) Cellular strategies of axonal pathfinding. Cold Spring Harb Perspect Biol 2:a001933. CrossRef Medline

Redies C, Inuzuka H, Takeichi M (1992) Restricted expression of N- and R-cadherin on neurites of the developing chicken CNS. J Neurosci 12: 3525-3534. Medline

Reeber SL, Sakai N, Nakada Y, Dumas J, Dobrenis K, Johnson JE, Kaprielian Z (2008) Manipulating Robo expression in vivo perturbs commissural axon pathfinding in the chick spinal cord. J Neurosci 28:8698-8708. CrossRef Medline

Reeber SL, Gebre SA, Sillitoe RV (2011) Fluorescence mapping of afferent topography in three dimensions. Brain Struct Funct 216:159-169. CrossRef Medline

Rhee J, Mahfooz NS, Arregui C, Lilien J, Balsamo J, VanBerkum MF (2002)
Activation of the repulsive receptor Roundabout inhibits N-cadherinmediated cell adhesion. Nat Cell Biol 4:798-805. CrossRef Medline

Rhee J, Buchan T, Zukerberg L, Lilien J, Balsamo J (2007) Cables links Robo-bound Abl kinase to N-cadherin-bound beta-catenin to mediate Slit-induced modulation of adhesion and transcription. Nat Cell Biol 9:883-892. CrossRef Medline

Richmond FJ, Courville J, Saint-Cyr JA (1982) Spino-olivary projections from the upper cervical spinal cord: an experimental study using autoradiography and horseradish peroxidase. Exp Brain Res 47:239-251. Medline

Sakai N, Kaprielian Z (2012) Guidance of longitudinally projecting axons in the developing central nervous system. Front Mol Neurosci 5:59. Medline

Sakano H (2010) Neural map formation in the mouse olfactory system. Neuron 67:530-542. CrossRef Medline

Shiau CE, Bronner-Fraser M (2009) N-cadherin acts in concert with Slit1Robo2 signaling in regulating aggregation of placode-derived cranial sensory neurons. Development 136:4155-4164. CrossRef Medline

Soriano P (1999) Generalized lacZ expression with the ROSA26 Cre reporter strain. Nat Genet 21:70-71. CrossRef Medline

Tissir F, Bar I, Jossin Y, De Backer O, Goffinet AM (2005) Protocadherin Celsr3 is crucial in axonal tract development. Nat Neurosci 8:451-457. Medline

Van Vactor D (1998) Adhesion and signaling in axonal fasciculation. Curr Opin Neurobiol 8:80-86. CrossRef Medline

Willis WD Jr (2007) The somatosensory system, with emphasis on structures important for pain. Brain Res Rev 55:297-313. CrossRef Medline

Wong GK, Baudet ML, Norden C, Leung L, Harris WA (2012) Slit1b-Robo3 signaling and $\mathrm{N}$-cadherin regulate apical process retraction in developing retinal ganglion cells. J Neurosci 32:223-228. CrossRef Medline

Xu Q, Grant G (2005) Course of spinocerebellar axons in the ventral and lateral funiculi of the spinal cord with projections to the posterior cerebellar termination area: an experimental anatomical study in the cat, using a retrograde tracing technique. Exp Brain Res 162:250-256. CrossRef Medline

Yusa K, Rad R, Takeda J, Bradley A (2009) Generation of transgene-free induced pluripotent mouse stem cells by the piggyBac transposon. Nat Methods 6:363-369. CrossRef Medline 